\title{
Passive avoldance: A variety of fear conditioning?
}

ROBERT J. BLANCHARD and D. CAROLINE BLANCHARD. Department of Psychology. University of Hawaii. Honolulu. Hawaii 96822

Step-in latencies and the proportion of time spent outside the shock situation were measured for three groups of rats. One group had received shock on stepping into the shock chamber, and had been allowed to escape the shock chamber. A yoked control group received the same number of shocks after being placed directly into the shock chamber. Escape was not permitted for these Ss. The final group had received no shock. Both shock groups differed reliably. from the nonshocked group on both response' measures. Differences between the two shocked groups were not significant. The results were interpreted as indicating that punishment of specific responses is not necessary for step-in passive aroidance performance.

Perhaps the only common feature of the many situations in which "passive avoidance" is measured, is that some highprobability active response becomes less probable following one or more shocks in the test situation. Two general views of the passive avoidance paradigm present different mechanisms to account for these decrements (Church, 1963). The punishment view involves the assumption that the most important contingency in the passive avoidance paradigm concerns an emitted response and the punishment of that response. A contrary view emphasizes the importance of stimulus-shock contingencies resulting in avoidance of situational or specific stimuli associated with shock.

If passive avoidance conditioning is to be regarded as a variety of the punishment paradigm, it is necessary to be able to demonstrate that response probability decrements in passive avoidance situations are related to punishment of the response measured. If shock which was not contigent on a given response, results in decrements in that response, the punishment view of passive avoidance becomes unnecessary.

The present experiment therefore compared passive avoidance performance for three groups of rats. The experimental group received shock on stepping down into a distinctive chamber. This group was allowed to avoid further shock by leaving the shock chamber. A yoked control group received the same number and spacing of shocks as the experimental group after being placed directly in the shock chamber. They were not allowed to escape. A final group received no shock. A punishment view of this situation would predict that the experimental group's step-in latencies on a nonshocked test trial would be much greater than those of the other groups. Also, if escape from the shock situation was acquired on the basis of previous shock avoidance, the experimental group should be much superior on this measure to either the yoked control, or the nonshocked control groups.

\section{SUBJECTS}

The Ss were 21 female albino rats, 130-133 days of age, from the colony maintained by the University of Hawaii Department of Psychology.

The conditioning apparatus consisted of two wooden boxes with clear Plexiglas fronts, which were connected by a $5 \times 6$ in. opening. This opening could be closed by a black Plexiglas guillotine door. The larger, shock, box was $20 \times 20 \times 10$ in., painted black, with flooring of stainless steel bars. The smaller $(9 x$ $5 \times 6$ in.) box was painted white, with wood floors, and was illuminated by a $60 \mathrm{~W}$ incandescent bulb suspended over the center of the translucent Plexiglas ceiling. The wooden flooring of the smaller box was $1 / 2$ in. above the level of the grid floor of the larger box. The flooring of the smaller box was mounted on microswitches connected to clocks. The grid flooring of the larger box was connected to a Grason-Stadler E1064-GS scrambled shock source. The duration and presentation of shocks were automatically controlled.

\section{PROCFDURE}

The experimental (E) Ss were placed individually in the smaller chamber, with the door lowered. After 2 sec. the door was raised, permitting access to the larger chamker. When the $S$ placed all four feet on the grids of the larger chamber, it received a $1.0 \mathrm{~mA}$ shock. $1 \mathrm{sec}$ in duration. Additional shocks were given at $10 \mathrm{sec}$ intervals as long as the $S$ remained in the shock chamber. which it could leave by returning through the open guillotine door. Each yoked control (YC) $S$ was placed directly in the larger chamber, and received the same number and spacing of shocks as the immediately preceding F S. The guillotine door leading to the smaller compartment was closed when these Ss were run. The nonshocked control (C) Ss were treated identically to the YC Ss, except that no shocks were given to this group. All Ss were run for a total of 120 sec.

All Ss were tested $2 \mathrm{~h}$ after training. Each $\mathrm{S}$ was placed in the smaller chamber, with the guillotine door closed. After $2 \mathrm{sec}$ the door was opened, and the latency to enter the larger chamber was measured. Total time spent in the smaller compartment. during the $120 \mathrm{sec}$ test session. was also measured. No shocks were given during the test trial.

\section{RESULTS AND DISCUSSION}

Mean latency to enter the larger compartment was $2.43 \mathrm{sec}$ for the C Ss, $59.28 \mathrm{sec}$ for the YC Ss, and $88.71 \mathrm{sec}$ for the E Ss. Analysis of variance indicated that these group scores differed reliably $(F=7.73, \mathrm{df}=2 / 18 . \mathrm{p}<.01)$. Subsequent $t$ tests showed that both the $E$ and the $Y C$ groups differed from the $C$ group $(t=3.87, d f=18 ., p<.005 ;$ and $t=2.55 . \quad d f=18 . p<.025$. respectively). The YC Ss did not reliably differ from the $E$ Ss $(t=1.32, \mathrm{df}=18, p>.05)$. A similar pattern was observed with the percentage of time spent in the smaller. nonshocked compartment. The C Ss spent $20.30 \%$ of the $120 \mathrm{sec}$ period in the smaller compartment, in contrast to $70.50 \%$ for the YC Ss and $79.20 \%$ for the E Ss. Again analysis of variance showed the group differences to be reliable $(F=8.17, \mathrm{df}=2 / 18, \mathrm{p}<.01)$. Subsequent $t$ tests indicated that the $C$ Ss differed from both the $E$ and the $Y C S s$ on this measure $(t=3.58 . \mathrm{d} f=18, \mathrm{p}<.01$. and $\mathrm{t}=3.02$, $\mathrm{df}=18, \mathrm{p}<.01)$. The $\mathrm{YC}$ group again did not differ from the $E$ group $(t=.56 . d f=18 . p>.05)$.

The present results therefore indicate that performance in a step-in passive avoidance situation does not greatly rely on the association of shock with the response of stepping into the shock situation. The present results also indicate that avoidance of a situation in which shock has been given is not greatly improved by previous successful escape experience in that situation. Since neither a specific response suppression mechanism nor a specific response learning mechanism can account for the performance of the present YC group, it would appear more parsimonious to assume that passive avoidance performance is largely based on the acquisition of fear.

In order for a fear hypothesis to account for the present findings, however, it may be necessary to postulate that fear elicits pre-experimentally acquired responses. including avoidance of distant fear eliciting stimuli, and escape from such stimuli when they are present and when a means of escape is readily apparent. Blanchard, Dielman, \& Blanchard (1968) have reported that shock in an inescapable situation produces immobility lasting for several hours, which is congruent with the notion that fear may elicit specific responses which vary with certain characteristics of the fear eliciting stimuli.

It might be noted that these three postulated reactions-failure to approach distant stimuli associated with shock. escape from stimuli associated with shock, and immobility in the presence of such stimuli when escape is not possible-may be features of both active and passive avoidance situations. However, in contrast to passive avoidance, many active avoidance situations involve a response which must be learned in the avoidance situation (e.g. 
bar pressing, wheel turning) in order to avoid further shocks. Thus, the results of most passive avoidance studies may reflect only the interactions of the responses elicited by fear, while active avoidance performance may involve both the learning of a specific avoidance response and the reactions elicited by fear producing stimuli.

\section{REFERENCES}

Blanchard, R. J., DielmaN, T. E., \& Blanchard, D. C. Prolonged aftereffects of a single foot shock. Pyychonomic Science, 1968, 10, 327-328.

CHURCH, R. M. The varied effects of punishment on behavior. Psychological Review, 1963, 70, 369-402. 